\title{
Social Media Influence on Health Belief
}

\author{
Farahana Binti Nadzri \\ Malaysian Biotechnology Information Centre, Monash University Malaysia, \\ Bandar Sunway, Selangor Darul Ehsan
}

\begin{abstract}
In this era of information or also known as Computer Age, Digital Age, or New Media Age, the public is not only able to access information with a stroke of their fingers but also create vast information for others. The newer generations of smartphones, computers, and tablets have made information omnipresent and easily accessible through the social media platform. But are the authorities and experts using this platform effectively to reach out to the public and dispel misinformation and pseudoscience? With citizen journalists in the rise, there is a greater demand for experts to make their voice heard. Social media has become an "official" source of information on science for many. These include Facebook, Instagram, Twitter, Tick Tock, LinkedIn, YouTube and many more. According to a survey done by Global Web Index, internet users are spending an average of 2 hours and 22 minutes per day on social media. It influe nces public opinion and decision making process. Organic food, alternative treatment for cancer and other diseases, genetically modified foods, slimming products and vaccination are some of the trending science news in social media. It is time health and medical experts step up and use the social media platform to provide science-based information to the public and dispel fake news, misinformation and fear mongering. This talk will present the different types of social media platforms, their demographics and distinct characters of each platform. The different strategies to maximize the media impression will also be discussed.
\end{abstract}

